\title{
Articulaciones transfronterizas de la violencia: relatos femeninos en la Triple Frontera del Paraná*
}

\section{Cross-border Articulations of Violence: Women's Stories in the Triple Border Area of Paraná}

\author{
Menara Guizardi** \\ (D) https://orcid.org/0000-0003-2670-9360 \\ Consejo Nacional de Investigaciones Científicas y Técnicas, Argentina \\ Universidad de Tarapacá, Chile \\ menaraguizardi@yahoo.com.br
}

\section{Eleonora López Contreras ${ }^{* * *}$ \\ (1) https://orcid.org/0000-0003-2670-9360 \\ Pontificia Universidad Católica de Chile \\ eleonoralopezcontreras@gmail.com}

* La investigación que dio origen a este artículo fue financiada por la Agencia Nacional de Investigación Desarrollo de Chile, a través del proyecto Fondecyt 1190056: "The Boundaries of Gender Violence: Migrant Women's Experiences in South American Border Territories".

** Doctora en Antropología Social y máster en Estudios Latinoamericanos por la Universidad Autónoma de Madrid, España. Cientista Social por la Universidade Federal do Espírito Santo, Brasil. Sus principales temas de investigaciones son: migraciones, fronteras, violencia de género en territorios sudamericanos.

** Doctoranda en Sociología por la Pontificia Universidad Católica de Chile. Sus líneas de estudio versan sobre sufrimientos sociales, racismo, infancias migrantes y estudios comparados.

cómo citar: Guizardi, M., López Contreras, E., Valdebenito, F. (2021). Articulaciones transfronterizas de la violencia: relatos femeninos en la Triple-frontera del Paraná. Secuencia (111), e1853. Dor: https://doi. org/10.18234/secuencia.v0i111.1853 


\section{Felipe Valdebenito ${ }^{* * *}$ \\ (D) https://orcid.org/0000-0002-4617-8520 \\ Universidad Católica del Norte, Chile \\ valdeb.felipe@gmail.com}

Resumen: Analizamos los relatos de 30 mujeres paraguayas sobre sus experiencias de violencia entre Ciudad del Este (Paraguay) y Foz de Iguazú (Brasil). El objetivo es caracterizar multidimensionalmente estas experiencias y su impacto en la presencia femenina en el espacio público. Presentaremos los debates teóricos sobre el concepto de violencia, estableciendo sus vinculaciones con los mandatos de género y con los territorios fronterizos latinoamericanos. Luego, definiremos la metodología de la investigación, desarrollada a partir del Extended Case Method y de la etnografía multisituada y caracterizaremos el perfil de las entrevistadas. Los apartados cuatro, cinco y seis constituyen la aportación original del artículo: adentran al análisis de los relatos de las mujeres sobre la violencia en Ciudad del Este, en el cruce fronterizo y en Foz de Iguazú. Finalizamos presentando los hallazgos del estudio, mostrando que las estrategias de movilidad femeninas se estructuran a partir del imperativo de sortear las experiencias violentas.

Palabras clave: mandatos de género; frontera; violencia; sexismo; Triple Frontera del Paraná.

Abstract: We analyze the stories of 30 Paraguayan women about their experiences of violence between Ciudad del Este (Paraguay) and Foz de Iguazú (Brazil). The aim is to characterize these experiences and their impact on the female presence in public space multidimensionally. We will present the theoretical debates on the concept of violence, establishing its links with gender mandates and Latin American border territories. We will then define the research methodology, developed from the Extended Case Method and multisited ethnography, and characterize the profile of the interviewees. Sections four, five and six constitute the original contribution of the article, analyzing women's stories of violence in Ciudad del Este, at the border crossing and in

**** Doctorante en Antropología por la Universidad Católica del Norte, Chile. Líneas de interés: historia del norte chileno, estudios fronterizos, migraciones, urbanismo. 
Foz de Iguazú. We conclude by presenting the findings of the study, showing that female mobility strategies are structured by the imperative of avoiding violent experiences.

Keywords: gender mandates; border; violence; sexism; Tri Border Area of Paraná.

Recibido: 8 de mayo de 2020 Aceptado: 10 de noviembre de 2020 Publicado: 31 de agosto de 2021

\section{INTRODUCCIÓN}

F ste artículo analiza los relatos de 30 mujeres paraguayas sobre sus expeCriencias de violencia en los espacios públicos de la Triple Frontera del Paraná (entre Argentina, Brasil y Paraguay). ${ }^{1}$ Nos centraremos en las localidades de Ciudad del Este y Foz de Iguazú que se ubican, respectivamente, del lado paraguayo y del lado brasileño de estas fronteras, y están conectados por el Puente de la Amistad (que cruza el río Paraná).

Se trata de un territorio internacionalmente reconocido, constituyendo la región fronteriza más transitada de Sudamérica (Agulló, 2017). Su crecimiento empezó en los años setenta con la construcción de la hidroeléctrica de Itaipú (1975-1986), entre Brasil y Paraguay, y con el establecimiento de la zona franca en Ciudad del Este (Renoldi, 2013, p. 125). Empero, la región sólo ganó notoriedad regional en los noventa, cuando asumió un papel estratégico para el Mercosur, catalizando un intenso flujo de personas (Albuquerque, 2012), mercancías (Sausi y Oddone, 2010) y turismo (Cury y Fraga, 2013). La zona cobija, además, una serie de actividades ilícitas (Costa y Schulmeister, 2007) que, frecuentemente, derivan en violencia de género (Barvinsk, 2014; OIT, 2002; Zsögön, 2013). Diversos estudios coinciden en que dicho territorio constituye un ámbito de vulneraciones para las mujeres paraguayas y que esta realidad responde a factores de larga duración.

${ }^{1}$ La Triple Frontera está conformada por seis municipios que contabilizan más de 800000 personas: Puerto Iguazú (Argentina); Foz de Iguazú (Brasil); Ciudad del Este, Presidente Franco, Hernandarias y Mingua Guazú (Paraguay) (Kleinschmitt, 2016, p. 41). 
Estos aluden a la particular historia de formación de estas fronteras desde la guerra del Paraguay (1864-1870), cuando este país enfrentó a la alianza entre Brasil, Argentina y Uruguay, perdiendo parte significativa de su territorio y cerca de $90 \%$ de su población masculina (Souchad, 2011, p. 134). Desde este conflicto, se engendraron imaginarios persistentes sobre las mujeres paraguayas (Potthast, 2001; 2006). Por un lado, ellas fueron representadas como objeto de expoliación sexual y laboral por los países vecinos (Bethell, 1996). Por otro, como grandes responsables de la reconstrucción económica y del cuidado familiar en Paraguay (Barrero-Valinotti, 2011, 2013). Este discurso naturalizador de la sobrecarga femenina se yuxtapuso a representaciones de la identidad nacional paraguaya, generalizando mandatos de género que convierten dicha sobrecarga en imperativo social (Soto, 2009).

Actualmente, muchas paraguayas establecen dinámicas laborales que contemplan cruces fronterizos diarios desde Ciudad del Este a Foz, donde trabajan en los negocios de Vila Portes, barrio comercial aledaño al Puente de la Amistad. Allí, ellas son la mano de obra predominante en las tiendas de ropa y calzado, en las bodegas de importación y venta de ropa usada, en los puestos callejeros autogestionados de venta de accesorios, vestimentas y calzados, en la atención y cocina de restaurantes y en la venta ambulante de verduras, hierbas y ajo. Trabajan, además, como empleadas domésticas en residencias particulares en barrios de la ciudad. Estos nichos laborales suelen compaginarse con el contrabando a pequeña escala de productos variados. Del lado paraguayo de la frontera -en el centro de Ciudad del Este, también en las inmediaciones del paso hacia Brasil-, ellas protagonizan un ingente despliegue comercial. Trabajan como vendedoras, administradoras o propietarias de los puestos callejeros, donde comercializan ropa de cama, útiles domésticos, vestimentas y accesorios. Se desempeñan, además, como vendedoras de las grandes tiendas (el comercio en las tiendas de mediana escala está caracterizado por el protagonismo masculino).

El objetivo de nuestro análisis es describir, a través de la síntesis de los relatos femeninos, las diferentes configuraciones de la violencia enfrentada por las mujeres paraguayas en este territorio. Mostraremos que se trata de un fenómeno multidimensional: que involucra diversos ejes de sus vidas, expresándose en su inserción económica y en sus posibilidades/restricciones de desplazamiento. Además, mostraremos que estas experiencias están presentes del lado paraguayo de la frontera, en los cruces fronterizos y en el espacio 
público de la ciudad brasileña del trifinio, manifestándose en cada uno de estos ámbitos de forma específica.

El artículo estará dividido en seis secciones subsecuentes a esta introducción. En el segundo apartado, sintetizamos las categorías centrales de nuestro estudio de caso: definiremos el concepto de violencia, estableciendo sus vinculaciones con los mandatos de género, con la escisión entre espacios público y privado y su manifestación en territorios fronterizos latinoamericanos. Luego, definimos la metodología de la investigación y caracterizamos el perfil de las entrevistadas. Los apartados cuatro, cinco y seis adentran al análisis de los relatos de las mujeres y abordan, respectivamente, sus narraciones sobre la violencia en Ciudad del Este, en el cruce fronterizo y en Foz de Iguazú. Finalizamos con las principales conclusiones del estudio.

\section{DEBATES TEÓRICOS}

El punto de partida teórico de nuestra investigación es la discusión sobre la violencia y su relación con las desigualdades de género. Como indican Garriga y Noel (2010), es recomendable situar la categoría "violencia" para evitar usar el concepto de forma ambigua y difusa, aplicándolo a toda gama posible de fenómenos y espacios. Así, conviene explicitar dos elementos iniciales. Primero, nos centraremos en las manifestaciones específicas de violencia relacionadas con las identidades de género y con la división sexual del trabajo. ${ }^{2}$ Segundo, comprendemos que la violencia opera dialécticamente en la construcción/deconstrucción de lazos sociales, articulando formas específicas de significación y simbolismo (Garriga y Noel, 2010, pp. 108-113). Pero para entender cómo este mecanismo opera sobre las mujeres, habría que explicitar que este se enmarca en procesos de dominación masculina de larga duración (Guizardi, López, Nazal y Valdebenito, 2017, p. 32).

${ }^{2}$ En los años noventa, las ciencias sociales cuestionaron las conceptualizaciones hasta entonces existentes sobre las identidades de género, la división sexual del trabajo y las jerarquías de poder que se establecen a partir de estos elementos. Estas discusiones produjeron un "giro de género", articulando cambios epistemológicos profundos en diversos campos disciplinarios (Lamas, 1986). Las varias acepciones dadas al género desde entonces constituyen una polisemia de difícil síntesis. Pero asumen, frecuentemente, un mínimo denominador común: el género constituye un conjunto de disposiciones y prácticas (simbólicas, económicas, políticas, culturales) que transforman socialmente el sexo biológico en un producto cultural (Lamas, 1999, p. 151). 
Con dominación masculina, aludimos al "orden social dominado por el principio masculino" (Bourdieu, 1998, p. 7), que se "constituye a través del principio de división fundamental entre lo masculino, activo, y lo femenino, pasivo, y ese principio crea, organiza, expresa y dirige el deseo, el deseo masculino como deseo de posesión, como dominación" (Bourdieu, 1998, p. 19). Este orden social constituye un campo conflictivo, activando procesos de dominio y poder que repercuten tanto sobre las mujeres como sobre los hombres (Mills, 2003, p. 42), generando disputas simbólicas que configuran a las diferencias, inclusiones y exclusiones de género (Butler, 2011, p. 39). Así, las desigualdades de género operan a través de al menos tres registros, todos profundamente relacionados con la violencia. Primero, como sistemas de significados y sentidos dominantes. Segundo, conforman relaciones sociales estructuradas en espacios sociales a modo de roles, prácticas, posibilidades de tránsito y/o permanencia. Tercero, son vividas por las personas como procesos componentes de su sentido de personalidad. A este conjunto de registros de diferenciación social lo denominamos mandatos de género. Es a través de estos mandatos que la dominación masculina se reproduce, permitiendo la permanencia y la transformación del orden patriarcal que, por su profundidad histórica y su carácter fundacional, constituye "el cimiento y pedagogía de todo poder" (Segato, 2016, p. 16). ${ }^{3}$

La estructuración del poder patriarcal conllevó, desde hace 11000 años, la construcción de una diferenciación entre el espacio público (apro-

${ }^{3}$ Segato (2010, p. 28) rechaza los planteamientos compartidos por Freud, Levi-Strauss y Lacan. Los tres definen el "asesinato del padre" como momento transicional hacia la cultura, estableciendo este acto violento como aquel que sedimenta la "firma" del contrato de "prohibición del incesto": pilar simbólico de la intervención social sobre la naturaleza en la especie humana (Levi-Strauss, 1969, pp. 42-43). Apunta que el asesinato del padre presupone una forma previa de acto violento: el establecimiento apriorístico de la dominación del patriarca sobre las mujeres de su grupo. Así, el contrato fundante tiene un origen anterior al asesinato del padre en la "apropiación por la fuerza de todas las hembras de su horda por parte del macho-padre-patriarca primitivo, como el crimen que da origen a la primera Ley, la ley del estatus: la ley del género" (Segato, 2010, p. 28). La prohibición del incesto constituiría un contrato entre pares, entre patriarcas, una vez establecida la ley fundante, basada en la apropiación violenta de las mujeres. A partir de este debate feminista, el patriarcado es definido como un fenómeno doble-dimensional. Por una parte, implicaría una dimensión "tópica", referente a la consecución de relaciones concretas, correspondiendo así al "nombre que recibe el orden de estatus en el caso del género", como "una estructura de relaciones entre posiciones jerárquicamente ordenadas que tiene consecuencias en el nivel observable" (Segato, 2010, p. 14). Pero, por otra parte, sería también el estrato simbólico conformador de todas las formas de simbolismo (Segato, 2010, p. 13). 
piado como signo del poder masculino) y el privado (donde las mujeres se repliegan, limitadas por el poder patriarcal) (Segato, 2016, p. 24). Las ciencias sociales tendieron, históricamente, a reproducir esta bipolaridad tomándola como un hecho, más que como el resultado de una pedagogía del poder. Consecuentemente, se reprodujo una visión de lo público que lo asocia al mundo productivo, al poder y a elementos de prestigio social y control político; mientras el espacio privado figuró desprovisto de estas cualidades y como tácitamente despolitizado (Segato, 2016, p. 25). Esta lectura contribuye a oscurecer las relaciones de desigualdad de género entre estos ámbitos, opacando que tanto el espacio público como el privado están atravesados por la influencia de los saberes y prácticas femeninas. Para superar esta bipolaridad analítica y las debilidades interpretativas que ella supone, autoras feministas vienen proponiendo retomar la noción de que "lo privado es público", pensando y traduciendo lo doméstico en términos públicos y viceversa (Segato, 2016, pp. 25-26). Adherimos a este giro analítico buscando identificar en las diferentes esferas por las cuales transitan las mujeres paraguayas (la pública y la privada; de un lado y de otro de las fronteras y en su cruce), la articulación de las formas de violencia masculina y, simultáneamente, las respuestas que ellas dan a estas problemáticas a partir de conocimientos que están profundamente vinculados al espacio doméstico y a las redes femeninas.

Paralelamente, acompañando el debate de Hernández y Rodríguez (2015), asumimos que la violencia vinculada a la dominación masculina entrecruza y articula los espacios públicos y privados. Ellas cumplen, en las sociedades patriarcales, una función central "en la reproducción de la economía simbólica del poder cuya marca es el género", constituyendo un acto necesario para la restauración de ese poder (Segato, 2010, p. 13). Además, se materializan como un cuadro sistémico de pequeñas y medianas agresiones de espectro variado, a modo de "sexismo". El término alude a formas de expresión de la violencia de género que "de manera sutil y en disimulo, transitan vertical, horizontal y circularmente entre los distintos agentes" (Hernández y Rodríguez, 2015, p. 130). En estos tránsitos, Hernández y Rodríguez (1015) afirman:

El uso de la fuerza física - golpes, violación y abuso cotidiano- no es el único medio de ejercitar violencia. El sexismo es, de entre todas las formas de la violencia de género, una de las más arcaicas y persistentes. Este se refiere a la discriminación basada en el sexo (Lamas, 1998) [...]. El sexismo alude entonces al ejercicio del poder para mantener en situación de inferioridad, subordi- 
nación, explotación al sexo opuesto, en tanto valoración (en las dimensiones cognitiva, afectiva y conductual) que se hace de una persona atendiendo a la categoría sexual biológica a la que ésta pertenece puede ser etiquetada como negativa o como positiva, y apunta tanto a mujeres como a los hombres (Expósito, Moya y Glick, 1998), no obstante, hay cierta tendencia a circunscribir cualidades negativas -sexistas- hacia las mujeres (p. 130).

El sexismo aparece, entonces, como un cuadro general que enmarca la dominación masculina y reproduce sus normas como un "deber ser": un organizador semántico de los procesos de subordinación. Esta articulación simbólica facilita el avance hacia otras formas de violencia (físicas, por ejemplo). El sexismo se reproduce a través de diversos mecanismos clasificatorios (como la estigmatización de las mujeres que sufren violencias, o que las denuncian).

La formación de los Estado-nacionales significó, desde finales del siglo XVIII, articulaciones específicas para esta densa relación entre la violencia, la dominación masculina y las mujeres (Yuval, 1993, p. 633). En la mayor parte de los proyectos Estado-nacionales latinoamericanos, ellas figuraron como elementos constitutivos de la cultura nacional, pero subordinadas al carácter viril de la nación. Su rol como reproductoras biológicas las yuxtapuso, ideológicamente, a la función de transmisoras de la "cultura nacional" (Yuval, 1993, p. 636). La concepción de una supuesta homogeneidad racial respaldó este concepto de cultura nacional y el de ciudadanía: el "control" de las capacidades reproductivas de las mujeres devino un elemento central para los ideales elitistas de homogeneidad nacional. De ahí que la movilidad femenina entre fronteras nacionales sea un problema político para los Estados y para el marco político sexista que los respalda.

Actualmente, diversas investigaciones desarrolladas en contextos fronterizos asumen que dichos territorios condensan la violencia estructural y de género, articulando la subordinación que las mujeres viven en el marco de los Estados-nacionales a las desigualdades económicas, políticas y sociales a escala global (Morales y Bejarano, 2009, p. 420). En las ciencias sociales, estas problemáticas fueron visibilizadas en los ochenta, con los estudios sobre las movilidades humanas en la frontera México-Estados Unidos. Desde entonces, las aportaciones de investigadoras latinoamericanas en esta frontera constituyen una contribución central a las ciencias sociales (Lugo, 1990; Woo, 2004; Monárrez, 2013; Téllez, 2008; Segato, 2013). Entre las varias conclusiones de estos estudios, destacamos tres. 
Primero, apuntan a que la vulnerabilidad laboral que las mujeres enfrentan en las fronteras se extiende al ámbito doméstico, en sus relaciones con sus parejas y con los miembros masculinos de sus familias (Molina, 1985, p. 33). Segundo, que las mujeres migrantes indocumentadas enfrentan una mayor cantidad de violaciones de derechos humanos en el cruce de fronteras: la condición de género contribuye al encadenamiento de violencias a lo largo del trayecto migratorio (Woo, 2004, p. 74). Tercero, unas 400 mujeres que trabajaban en las maquilas de Ciudad Juárez (México) fueron asesinadas brutalmente entre 1994 y 2004. Estos feminicidios atestiguaban la forma como los hombres buscaban controlar con la violencia el protagonismo laboral y la parcial autonomía económica que ellas asumieron en este territorio (Arriola, 2007, p. 603). ${ }^{4}$

Los debates sobre violencia y género en fronteras sudamericanas sólo empezaron a cobrar protagonismo desde el año 2000. Los nuevos estudios emergieron debido al creciente interés internacional sobre la problemática de la trata humana. ${ }^{5}$ El tema se adentró fuertemente en la agenda de investigadores(as) que trabajan en la Triple Frontera del Paraná. Sus diagnósticos apuntan a que la trata humana en esta frontera está articulada con los circuitos turísticos y comerciales (oIT, 2002).

Dos tipos específicos de trata humana con fines sexuales operarían en esta región: de niñas y adolescentes (Seaman, 2012; Tarducci, 2006; Zsögön, 2013) y de mujeres mayores de edad (Barvinsk, 2014). Analizando el segundo tipo, Barvinsk (2014) dilucida que la Triple Frontera constituye una "zona de servicios" que emplea predominantemente la mano de obra femenina informal. En ella, los límites entre el comercio y el crimen se desdibujan frecuentemente (Renoldi, 2013). En estas interacciones liminales, las mujeres se involucran en actividades criminales, exponiéndose a las redes de trata. Generalmente, son cooptadas por un familiar, pareja, vecino o amigo cercano. Los límites entre violencia de género y lazo familiar o afectivo serían tan limi-

${ }^{4}$ Monárrez (2013), analizando estos casos de mujeres secuestradas, torturadas, mutiladas, violentadas, asesinadas y que tuvieron sus cuerpos arrojados al desierto en Ciudad Juárez, propone un concepto que articula la dimensión micro y macro escala de este fenómeno: lo denomina feminicidio sexual sistémico.

${ }^{5}$ En 2002, la Organización Internacional del Trabajo declaró que prevenir y punir las redes ilegales de trata de mujeres con fines sexuales en las zonas fronterizas sudamericanas era prioritario, dada la gravedad de la vulneración de los derechos humanos en estas redes (OIT, 2002, p. 16). 
nales en sus vidas como el cruce entre legalidad e ilegalidad en el desempeño de las actividades y servicios fronterizos (Barvinsk, 2014).

Otro de los campos de investigación desarrollados en esta Triple Frontera refiere a las movilidades transfronterizas y su interrelación con las transformaciones de los lazos familiares, roles de género y la sobrecarga (re)productiva femenina (Profit, 2015). Báez (2017), por ejemplo, realizó entrevistas a profundidad con trabajadoras domésticas paraguayas empleadas en Foz de Iguazú. Su estudio demuestra que las mujeres optan por una vida transfronteriza a raíz de procesos de marginación social, económica y laboral en su país de origen. Así, la precariedad laboral en Paraguay y la rentabilidad cambiaria de la moneda brasileña impulsa a las mujeres paraguayas a buscar trabajos domésticos en Foz. Una vez que se insertan en estas labores en territorio brasileño, su vulnerabilidad tiende a incrementarse: los empleadores usan su condición de indocumentadas para explotarlas (Báez, 2017). La sobrecarga de trabajos domésticos y de cuidado termina por extender su jornada laboral por sobre los límites legales. Asimismo, ellas cobran menos que lo establecido legalmente en Brasil y sufren procesos de discriminación racial, étnica y de género. De esta forma, las tareas domésticas constituyen un mercado laboral transfronterizo que traspasa la responsabilidad de la reproducción social de las familias brasileñas a las mujeres paraguayas, quienes desarrollan estas funciones bajo condiciones de explotación, precariedad, denigración y vulneración (Profit, 2015). Nuestro estudio confirma parte de estas aseveraciones, pero devela otras dimensiones de esta experiencia femenina transfronteriza.

\section{METODOLOGÍA Y CARACTERIZACIÓN MUESTRAL}

Los resultados analizados derivan de un estudio de caso etnográfico ${ }^{6}$ que Guizardi viene desarrollando desde 2018 en la Triple Frontera del Paraná, sobre las prácticas transfronterizas de las mujeres paraguayas. Estas experiencias etnográficas originaron un proyecto de investigación más amplio, iniciado en abril de 2019, en el que participan también López y Valdebenito. En el marco

${ }^{6}$ Comprendemos la etnografía como la observación sistemática de los contextos sociales con la finalidad de participar de ellos, registrarlos, analizarlos y construir relatos (Guber, 2001, p. 12). La perspectiva metodológica etnográfica busca la interacción crítica entre sujetos de estudio e investigadores, constituyéndose simultáneamente como un enfoque, un método y un ejercicio intersubjetivo (Guber, 2001, p. 12). 
de este proyecto, viajamos entre julio y agosto de 2019 a la Triple Frontera para desarrollar nuestro trabajo de campo. En dicha etapa, circulamos por los espacios laborales de las mujeres paraguayas entre Puerto Iguazú, Foz de Iguazú y Ciudad del Este. Registramos estas informaciones en 22 relatos etnográficos extensos, en más de 500 fotografías y en 47 videos. Profundizando en la recopilación de material cualitativo, realizamos 30 entrevistas de historia de vida $^{7}$ con mujeres paraguayas que trabajan entre el lado paraguayo y el brasileño de la Triple Frontera. ${ }^{8}$ La técnica permitió recopilar los relatos de las mujeres sobre sus experiencias de violencia del lado paraguayo y del lado brasileño de la frontera.

Terminado el trabajo de campo, las entrevistas y diarios etnográficos fueron transcritos y categorizados con el software de análisis de discurso MaxQDA. La matriz que creamos para dicho análisis contemplaba seis macrocategorías, ${ }^{9}$ divididas en 130 códigos. En este texto, analizamos los relatos de las mujeres que fueron agrupados bajo la macrocategoría "Experiencias de la violencia”. Abordaremos, particularmente, las narraciones clasificadas bajo los códigos que refieren a la manifestación de dichas violencias en el espacio público. ${ }^{10}$

Algunos criterios de selección de las entrevistadas fueron aplicados para atender a nuestros objetivos de investigación. En este sentido, la muestra contempla mujeres en edad económicamente activa (entre 15 y 65 años) que compaginan actividades productivas y reproductivas. Esto responde a nues-

${ }^{7}$ La entrevista de historia de vida consiste en una estrategia flexible de interacción dialógica en la que no hay preguntas preformuladas (Alberti, 2005). Se construye a partir de la sugerencia a la entrevistada de que narre su vida cronológicamente, comenzando por la historia de sus abuelas(os).

${ }^{8}$ Nos concentramos en estas dos localidades porque ellas catalizan la mayor parte de las actividades económicas y del flujo humano de esta región fronteriza (Cury y Fraga, 2013, pp. 470-471). Asimismo, a través de nuestra observación etnográfica y de la revisión de los estudios previos, constatamos que las movilidades femeninas paraguayas en esta región son más intensas entre dichas ciudades, que están profundamente articuladas en términos productivos, comerciales y de mercado laboral.

${ }^{9}$ A saber: 1) construcciones de la frontera; 2) trayectorias de las mujeres fronterizas; 3 ) inserción de las mujeres fronterizas; 4) configuraciones del cuidado fronterizo; 5) experiencias de violencia, y 6) conexiones fronterizas sudamericanas.

${ }^{10}$ A saber: 1) violencia en la inserción productiva; 2) discriminaciones raciales/xenófobas; 3) violencia machista en el espacio público; 4) violencia estructural (ausencia de protección social estatal en salud, educación, jubilación, infraestructura); 5) violencia de las fuerzas de seguridad estatales, y 6) relación entre violencia y movilidad fronteriza. 
tro interés de comprender la relación entre sus actividades productivas, movilidades y experiencias de violencia en el espacio público.

El cuadro 1 aporta una síntesis sobre nuestras colaboradoras. ${ }^{11}$ Entre ellas, dos tenían de 15 a 25 años; doce tenían de 26 a 35; cuatro tenían de 36 a 45 ; seis tenían de 46 a 55, y seis de 56 a 65 años. La mayoría ( 29 mujeres) tuvo acceso a la educación formal; sólo una no frecuentó la escuela. Entre las que realizaron estudios, seis completaron la primaria y diez no; cinco poseían la secundaria completa, dos poseían educación universitaria incompleta, una poseía carrera técnica completa y dos eran universitarias. En total, 17 mujeres estaban casadas; ocho se declararon separadas, tres convivían con la pareja (unión de hecho) y dos estaban solteras. La mayoría (25) tenía hijos(as), pero una de ellas no quiso responder las preguntas sobre este tema. Para las 24 que respondieron, el número de hijos(as) variaba de 1 a 9 en total. Entre ellas, ocho mujeres fueron madres adolescentes (entre los 16 y 18 años). Las demás iniciaron su experiencia de maternidad entre los 20 y 30 años.

Entre las entrevistadas, 27 mujeres declararon vivir en Ciudad del Este; dos en Foz de Iguazú y una en San Miguel de Iguazú (villa rural brasileña, a 42 kilómetros de Foz). Pero, cuando observamos dónde desempeñan su actividad productiva, los cómputos son otros: 16 se desempeñan en Foz, ocho en Ciudad del Este, y seis atravesando mercancías entre Brasil y Paraguay. Así, la mayor parte de ellas vive en Paraguay, pero 22 desempeñan actividades productivas que las desplazan cotidianamente al lado brasileño. Encontramos diferentes nichos de inserción laboral y modalidades de empleo entre las entrevistadas. Es posible agruparlos en tres grupos. Primero, las mujeres que trabajan en un espacio fijo de Foz (16 en total): ocho son vendedoras y regentan puestos callejeros (cuatro de ellas venden ropa/accesorios/calzado y cuatro alimentos); dos son vendedoras contratadas de tiendas de ropa; dos trabajan en restaurantes (una como camarera, otra como cocinera); una trabaja como operaria de un frigorífico; dos como auxiliares de limpieza (una en residencia particular, otra en oficina pública); una como funcionaria municipal. Por otra parte, están aquellas que pasan diariamente por Foz para buscar productos que serán contrabandeados a Ciudad del Este (seis en total). Entre ellas, dos llevaban aceite y frutas de Brasil a Paraguay en cantidades importantes. Otras cuatro realizaban un contrabando a pequeña escala, de produc-

${ }^{11}$ Conforme a los reglamentos éticos de la investigación, las entrevistadas tienen su identidad protegida bajo seudónimos/iniciales por ellas elegidos. 


\section{Cuadro 1. Perfil de las entrevistadas}

\begin{tabular}{|c|c|c|c|c|c|}
\hline $\begin{array}{l}\text { Seudónimo/ } \\
\text { iniciales }\end{array}$ & $\begin{array}{l}\text { Nacionali- } \\
\text { dad }\end{array}$ & Edad & Ocupación & $\begin{array}{l}\text { Estado } \\
\text { civil }\end{array}$ & Ciudad de residencia \\
\hline EPM & Paraguaya & 26 años & $\begin{array}{l}\text { Vendedora de ajo y especias, puesto callejero (Foz } \\
\text { de Iguazú) }\end{array}$ & Casada & Ciudad del Este (Paraguay) \\
\hline Sofía & Paraguaya & 31 años & $\begin{array}{l}\text { Contrabandista de aceite (de Foz de Iguazú a Ciu- } \\
\text { dad del Este) }\end{array}$ & Casada & Foz do Iguazú (Brasil) \\
\hline RBA & Paraguaya & 19 años & Camarera en restaurante (Foz de Iguazú) & Soltera & Ciudad del Este (Paraguay) \\
\hline Clara & Paraguaya & 39 años & $\begin{array}{l}\text { Cocinera en restaurante } \\
\text { (Foz de Iguazú) }\end{array}$ & Casada & Ciudad del Este (Paraguay) \\
\hline Guerrera & Paraguaya & 38 años & Operaria de Frigorífico (Foz de Iguazú) & Separada & San Miguel de Iguazú (Brasil) \\
\hline Avril & Paraguaya & 19 años & Camarera en Casino (Ciudad del Este) & Soltera & Ciudad del Este (Paraguay) \\
\hline Sonia & Paraguaya & 26 años & Vendedora de tienda (Foz de Iguazú) & Separada & Ciudad del Este (Paraguay) \\
\hline Silvia & Paraguaya & 51 años & Vendedora de ropa, puesto callejero (Foz de Iguazú) & Casada & Ciudad del Este (Paraguay) \\
\hline Talía & Paraguaya & 29 años & Vendedora de ropa, puesto callejero (Foz de Iguazú) & Separada & Ciudad del Este (Paraguay) \\
\hline Mía & Paraguaya & 26 años & Vendedora de ropa usada (Foz de Iguazú) & $\begin{array}{l}\text { Unión de } \\
\text { hecho }\end{array}$ & Ciudad del Este (Paraguay) \\
\hline Lirio Blanco & Paraguaya & 56 años & Vendedora de empanadas y Terere (Foz de Iguazú) & Separada & Ciudad del Este (Paraguay) \\
\hline Rosa 1 & Paraguaya & 43 años & $\begin{array}{l}\text { Recoge verduras desechadas por las bodegas de Foz } \\
\text { de Iguazú y las vende en Ciudad del Este }\end{array}$ & Separada & Ciudad del Este (Paraguay) \\
\hline
\end{tabular}




\begin{tabular}{|c|c|c|c|c|c|}
\hline $\begin{array}{l}\text { Seudónimo/ } \\
\text { iniciales }\end{array}$ & $\begin{array}{l}\text { Nacionali- } \\
\text { dad }\end{array}$ & Edad & Ocupación & $\begin{array}{l}\text { Estado } \\
\text { civil }\end{array}$ & Ciudad de residencia \\
\hline Alicia & Paraguaya & 29 años & $\begin{array}{l}\text { Recoge verduras desechadas por las bodegas de Foz } \\
\text { de Iguazú y las vende en Ciudad del Este. (Tam- } \\
\text { bién recoge zapatos) }\end{array}$ & $\begin{array}{l}\text { Unión de } \\
\text { hecho }\end{array}$ & Ciudad del Este (Paraguay) \\
\hline María 1 & Paraguaya & 46 años & Vendedora de alimentos (Foz de Iguazú) & Casada & Ciudad del Este (Paraguay) \\
\hline Rosa 2 & Paraguaya & 52 años & $\begin{array}{l}\text { Vendedora de ropa y calzado, puesto callejero (Foz } \\
\text { de Iguazú) }\end{array}$ & Casada & Ciudad del Este (Paraguay) \\
\hline Águila & Paraguaya & 31 años & $\begin{array}{l}\text { Trabajadora doméstica en residencia (Foz de } \\
\text { Iguazú) }\end{array}$ & Casada & Ciudad del Este (Paraguay) \\
\hline G & Paraguaya & 35 años & Realiza aseo en Casa do Migrante (Foz de Iguazú) & $\begin{array}{l}\text { Unión de } \\
\text { hecho }\end{array}$ & Ciudad del Este (Paraguay) \\
\hline Shakira & Paraguaya & 29 años & $\begin{array}{l}\text { Vende empanadas y tapioca, puesto callejero (Foz } \\
\text { de Iguazú) }\end{array}$ & Casada & Ciudad del Este (Paraguay) \\
\hline Antonia & Paraguaya & 62 años & Vende ropa en tienda (Foz de Iguazú) & Separada & Ciudad del Este (Paraguay) \\
\hline Rojo & Paraguaya & 56 años & Vende ropa, puesto callejero (Ciudad del Este) & Casada & Ciudad del Este (Paraguay) \\
\hline Paloma & Paraguaya & 35 años & Vende ropa, puesto callejero (Ciudad del Este) & Casada & Ciudad del Este (Paraguay) \\
\hline María 2 & Paraguaya & 46 años & Vende ropa, puesto callejero (Ciudad del Este) & Casada & Ciudad del Este (Paraguay) \\
\hline EA & Paraguaya & 46 años & Vende ropa, puesto callejero (Ciudad del Este) & Casada & Ciudad del Este (Paraguay) \\
\hline Lirio & Paraguaya & 29 años & Vende ropa, puesto callejero (Ciudad del Este) & Casada & Ciudad del Este (Paraguay) \\
\hline
\end{tabular}




\begin{tabular}{|c|c|c|c|c|c|}
\hline $\begin{array}{l}\text { Seudónimo/ } \\
\text { iniciales }\end{array}$ & $\begin{array}{l}\text { Nacionali- } \\
\text { dad }\end{array}$ & Edad & Ocupación & $\begin{array}{l}\text { Estado } \\
\text { civil }\end{array}$ & Ciudad de residencia \\
\hline Amada & Paraguaya & 58 años & $\begin{array}{l}\text { Vende ropa de cama y baño, puesto callejero (Ciu- } \\
\text { dad del Este) }\end{array}$ & Casada & Ciudad del Este (Paraguay) \\
\hline $\begin{array}{l}\text { Mujer } \\
\text { paraguaya }\end{array}$ & Paraguaya & 43 años & Vende ropa, puesto callejero (Ciudad del Este) & Casada & Ciudad del Este (Paraguay) \\
\hline Angélica & $\begin{array}{r}\text { Paraguaya/ } \\
\text { Brasileña }\end{array}$ & 58 años & $\begin{array}{l}\text { Funcionaria en una oficina municipal de atención } \\
\text { turística (Foz de Iguazú) }\end{array}$ & Separada & Foz de Iguazú (Brasil) \\
\hline Orquídea & Paraguaya & 52 años & $\begin{array}{l}\text { Recoge verduras desechadas por las bodegas de Foz } \\
\text { de Iguazú y las vende en Ciudad del Este }\end{array}$ & Casada & Ciudad del Este (Paraguay) \\
\hline Eulo & Paraguaya & 62 años & $\begin{array}{l}\text { Contrabando de frutas de Foz de Iguazú a Ciudad } \\
\text { del Este }\end{array}$ & Casada & Ciudad del Este (Paraguay) \\
\hline Fiona & Paraguaya & 24 años & $\begin{array}{l}\text { Recoge verduras desechadas por las bodegas de Foz } \\
\text { de Iguazú y las vende en Ciudad del Este }\end{array}$ & Separada & Ciudad del Este (Paraguay) \\
\hline
\end{tabular}

Fuente: elaboración propia con base al material etnográfico del proyecto Fondecyt 1190056. 
tos de bajo valor: recogían verduras y frutas desechadas por los comerciantes en las inmediaciones de la Central Estadual de Abastecimiento mayorista del lado brasileño (la CEASA), para lavarlos, limpiarlos, cortarlos y venderlos en Ciudad del Este. Algunas también recogían zapatos y ropa usada con este fin. Finalmente, estaban las que trabajan en un espacio fijo del lado paraguayo de la frontera (ocho en total): siete eran vendedoras de ropa o calzado en puestos callejeros de Ciudad del Este, y una era camarera en un casino.

Los datos sobre el lugar de origen de las entrevistadas revelan aspectos fundamentales para entender los patrones de inserción laboral y de acceso a educación formal. Permiten, además, vincular estos elementos con las experiencias migratorias familiares/personales. La mayoría de las entrevistadas (29) nació en diversas localidades de Paraguay (sólo una nació en la ciudad de San Pablo, en el estado brasileño homónimo), lo que indica la atracción migratoria que ejerce la Triple Frontera. Las nacidas en Paraguay procedían de al menos nueve diferentes departamentos: $:^{12}$ Alto Paraná (9), Caaguazú (6), Paraguarí (3), Asunción (3), Itapúa (2), Guairá (2), San Pedro (1), Concepción (1). Se observa, además, una elevada diversificación de los municipios de origen dentro de cada departamento (18 en total). Solamente cuatro de las entrevistadas nacieron en Ciudad del Este: 26 mujeres migraron a esta ciudad. ${ }^{13}$

\section{DEL LADO PARAGUAYO}

La mayoría de nuestras entrevistadas considera que la violencia machista es frecuente en Paraguay y en Brasil, pero asumen que los hombres paraguayos son más violentos:

I: Señora Rosa 2, ¿Usted cree que hay mucho machismo en Paraguay?, ¿mucho maltrato contra las mujeres?

E: Creo que sí. Creo que sí, porque en esta época hay muchas personas que se separan. Hay muchos hombres que matan a sus parejas. Creo que sí: hay mucho machismo.

${ }^{12}$ La república paraguaya está dividida en tres tipos de unidades internas denominadas (de mayor a menor): departamentos, distritos y municipios.

${ }^{13}$ Incluyéndose las tres que declaraban vivir en ciudades brasileñas (todas vivieron en Ciudad del Este antes de pasarse a territorio brasileño, pero ninguna nació allí). 
I: ¿Y acá en Brasil como lo ve?, ¿más o menos machismo?

E: Yo creo que igual... No... El paraguayo más (Entrevista a Rosa 2, 25 de julio de 2019).

Ellas mencionaron, además, que en Ciudad del Este hay violencia callejera contra las mujeres. Pero explicitan que esta ocurre cuando ellas "insisten" en moverse por ciertos espacios en horarios "inadecuados": "O sea, [la violencia] pasa más de noche. Para mí, es más de noche" (Entrevista a Lirio Blanco, 23 de julio de 2019). Al anochecer, la actividad comercial lícita cesa y los barrios céntricos, aledaños al Puente de la Amistad, son el escenario de actividades delictivas variadas (que, si bien también existen durante el día, son mucho más intensas por las noches). Según los testimonios, habría una especie de pacto respecto a la inseguridad, pues los ritmos y alternancias entre las actividades comerciales legales/ilegales requieren que existan momentos (el horario comercial diurno) en que el tránsito de trabajadoras y compradoras sea asegurado, garantizando el buen funcionamiento del comercio fronterizo. Así, es en la noche cuando las actividades delictivas se adueñan de las calles. Estas son comprendidas como un nicho masculino, dominado por hombres, ordenado por ellos. Hablamos entonces de dos fronteras de género: una que asocia la noche a lo masculino, y otra que asocia las actividades delictivas a la masculinidad. Estas fronteras entre seguridad e inseguridad movilizan inscripciones morales respecto de los derechos y potestades atribuidos a cada género: "Inseguridad, sí hay verdad [en Ciudad del Este]. Hay inseguridad, pero se lleva bien. Pero depende de la persona, la verdad. Si vos salís mucho, a hinchar las pelotas por ahí, quizás te pasa algo. Pero si sos de casa y te resguardas, trabajas, estudias, no pasas mucho peligro. Solamente en las noches" (Entrevista a Talía, 17 de julio de 2019).

En el discurso de Talía vemos cómo se produce una justificación moral que atribuye a las mujeres la responsabilidad de ser víctima de la violencia callejera. Esta justificación se respalda, a su vez, en mandatos de género: si las mujeres se quedan en sus casas, haciéndose cargo del ámbito doméstico, si trabajan y estudian, están seguras y no son destinatarias de la violencia. Estos mandatos se amparan en imaginarios sobre la limitación de las posibilidades de tránsito y las libertades femeninas (las mujeres no pueden salir a divertirse, menos por la noche). Se establece, así, una frontera moral entre las mujeres que pretensamente merecen la violencia (las que subvierten a los mandatos de género) y las que no (aquellas que cumplen dichos mandatos a rajatabla). En 
las entrevistas y observaciones etnográficas, constatamos que tantos los hombres como mujeres naturalizan estos mandatos e imaginarios morales.

Pero, ¿qué pasa en aquellos casos en los cuales el desempeño como "mujer que no merece la violencia" demanda cruzar el espacio público por la noche? Estos casos específicos requieren de la construcción familiar de mecanismos de protección. Un ejemplo es la situación relatada por Amada, vendedora de ropa en un puesto callejero de Ciudad del Este cuya hija, además de trabajar, estudia la universidad nocturna. Para asegurar su bienestar, "su papá la lleva a la facultad; la trae otra vez. La lleva a la facultad, todo de puerta a puerta, ¡Gracias a dios!" (Entrevista a Amada, 30 de julio de 2019). Aquí vemos cómo el cumplimiento del mandato ("si trabajas, si estudias, no pasas mucho peligro", como decía Talía) habilita moralmente la presencia de la joven en las calles por la noche, pero con la escolta de una figura masculina que la conduce de "puerta a puerta".

Los relatos establecen que las jerarquías de estratificación socioeconómica constituyen otras formas de frontera entre quienes son o no destinatarios de expresiones relacionales agresivas, humillantes o, incluso, de violencia física del lado paraguayo de la frontera. Las personas ubicadas en los grupos menos favorecidos de estas jerarquías son destinatarias del maltrato de parte de aquellas adscritas a los grupos con mayores recursos: "El trato: eso es la diferencia. En Paraguay, cuando nosotros estamos así, cuando estamos en un nivel más alto, le ves a una persona con nivel más bajo y la trata mal. Es bueno [vivir en Ciudad del Este] si tenés dinero. Si no tenés, es difícil; te tratan mal" (Entrevista a EA, 29 de julio de 2019).

Según las entrevistadas, estas circunstancias son aún más drásticas para las mujeres de los sectores sociales de menor poder adquisitivo, quienes sufren más discriminaciones que los hombres en condicionantes semejantes. El sexismo que caracteriza las relaciones sociales en Ciudad del Este marca profundamente el mercado laboral, condicionando las posibilidades de acceso a derechos y mejores sueldos. Paloma cuenta, por ejemplo, que el trabajo femenino es constantemente menospreciado, mientras las labores, atributos y capacidades masculinas son enaltecidas:

¿Qué querés que te diga? Es muy difícil, porque, hoy por hoy, una mujer al volante... Si no pasa rápido un atasco, dicen: "iEs mujer! Seguro, que es mujer”. Siempre es un poco menos la mujer. Nunca va a tener la voz de mando. Nunca la va a tener una mujer, por mucho que ella haga. $\mathrm{O}$, mientras solamente sea 
ella la que haga. Por ejemplo, una chica que trabaja aquí, también en la misma cuadra, trabaja todos los días. A esa mujer no se le da el valor que se le puede dar a un hombre trabajador. Esa es la diferencia de una mujer y un hombre: siempre va a ser así. O, lo que haga una mujer no es tan lindo como lo podría hacer un hombre. Un hombre lo haría mejor ¿Entiendes? (Entrevista a Paloma, 27 de julio de 2019).

Pero la visión pesimista de Paloma no la comparten las nuevas generaciones. Más joven, Avril confirma las desigualdades laborales machistas, pero relata un cambio de mentalidades y un proceso de feminización del mercado laboral local: "Algunos trabajos, sí, te pagan bien. En algunos, ya no tanto, que yo llegué a escuchar. Digamos que nosotras, las mujeres, tenemos dificultades muchas veces en trabajar. Por ahora, hoy en día, ya no tanto. Pero antes sí, porque había mucho machismo, y todo eso. Pero, ahora, hay más mujeres que hombres trabajando por ahora" (Entrevista a Avril, 16 de octubre de 2018).

\section{LA MOVILIDAD COMO RESPUESTA}

Los relatos permiten establecer que la movilidad de las mujeres es, frecuentemente, una estrategia para sobrellevar las violencias, para esquivarlas o para frenarlas. La capacidad de interrumpir los ciclos de violencia está centralmente vinculada con la posibilidad de desarrollar actividades económicas que les permitan hacerse cargo de los gastos de sus familias sin depender de la renta masculina. Muchas emprenden estrategias de movilidad con esta finalidad migrando desde localidades rurales de Paraguay hacia Ciudad del Este. Como mencionamos, entre nuestras 30 entrevistadas, identificamos un total de 18 diferentes localidades de origen en Paraguay. Solamente cuatro mujeres nacieron en Ciudad del Este: 26 migraron a esta localidad, casi todas provenientes de ámbitos rurales. Las que no nacieron en el campo eran la primera generación urbana de sus familias. Esto implica que su idioma materno sea el guaraní y que muchas de ellas hayan aprendido el castellano en edad mayor tras migrar a las ciudades. Esta especificidad lingüística se nota en varias de las respuestas. Así, la movilidad transfronteriza se establece como una alternativa posterior a la migración del campo a la ciudad: 
Y, no conviene quedarme en Campaña [localidad rural de origen], porque su mamá, cuando él [su pareja] no está, me maltrata mucho. Entonces, yo pensé que tengo hijos, tengo que salir adelante. Y vine a Ciudad del Este. Campaña es muy difícil. Para salir adelante es muy difícil. La gente mucho más salir en la ciudad. Porque, solamente en Campaña trabaja para comer. Sola, no, no, nada: no sobra nada. No puede tener nada, no puede hacer nada. Porque uno no hay trabajo. Porque hay más pobreza [...]. Hasta ahora es poca persona que trabaja. Trabaja y gana poquito, solo para sustentar (Entrevista a Lirio Blanco, 23 de julio de 2019).

Para algunas de ellas, las movilidades desde las localidades rurales de origen se estructuraron directamente a través del circuito del tráfico de drogas, que conecta los espacios productores en el campo paraguayo a las grandes metrópolis brasileñas. Este es el caso de G., que describe cómo la vulnerabilidad socioeconómica que enfrentaba en su localidad rural de origen (Campaña), aunada a la inestabilidad del empleo de su pareja, la llevó a trabajar transportando drogas hacia San Pablo (Brasil). Tras iniciar esta actividad, sufrió constantes amenazas de los traficantes para no interrumpir sus viajes. Llegó a realizar 19 traslados de droga, temiendo por su vida y la de sus hijos:

El señor [traficante] me decía que si no me voy [a San Pablo], o la cárcel o la muerte. Y eso es una amenaza. En ese momento, lo único que yo pensaba, porque no me daba tiempo ni de parar, era que mi suegra vive en Jardim Jupira [barrio de Foz], acá. Era donde nos íbamos a ir con las criaturas bebe. Tengo que llevar leche, pañal. Él no trabajaba [su pareja]. Yo solo la droga. Él buscaba trabajo; se iba dos días a hacer pintura y cosas así. No era trabajo seguro (Entrevista a G., 25 de julio de 2019).

En el relato, vemos cómo G. planea apartar a los hijos de la amenaza de los narcotraficantes del lado paraguayo llevándolos a la casa de su suegra en Foz, del lado brasileño. La responsabilidad de hacerse con los bienes materiales necesarios para sus hijos -leche, pañal- recae en ella, ya que su marido no trabaja. Así, cruzar hacia Brasil significaba la posibilidad de esquivar las presiones y el control ejercido por parte de las redes de narcotráfico, intentando dejar a sus hijos a salvo. Pero ella no llegó a ejecutar este plan. En su último viaje traficando fue detenida por la policía brasileña y encarcelada. El relato de G. sobre el día de su arresto muestra las vulnerabilidades y precariedades 
a que estaba expuesta. Desvela, además, su aprehensión sobre la situación de su hijo recién nacido, al que dejó con su suegra, y la intrincada relación entre sus responsabilidades familiares y su inserción en el tráfico:

A la mañana, le lleve a mi hijo [a la casa de su suegra]. A las 12 , yo tenía que salir. Él me esperaría en el kilómetro 7, el señor [traficante]. Llegué, dejé mi hijo y pasó el colectivo a buscar. Y yo lloraba y lloraba. Yo le daba de mamar. Le dejé la mamadera ese día. Y tenía un guantecito. Y ese guantecito, traía en mi mano. Y vine y rezaba para que dios me cuide. Ya me subí al colectivo "Expreso Guaraní” [empresa que conecta Paraguay y Brasil] y pasé la barranquilla. Y, en Matelandia [ciudad rural del extrarradio de Foz], me caí. Me dijo [la policía] que me baje [del vehículo]. Y, ahí, con el guantecito me quedé. Me interesaba sólo mi bebe: era lo único que me interesaba. Y no teníamos otra salida. Me cachearon y lloré demasiado. Me puso la pulsera [esposa]. Y, ahí, llorando, le dije a la policía todo: que no podía quedarme, que tenía un bebe de 42 días. Mi explicación era que no tenía solución; que prácticamente me obligó (Entrevista a G., 25 de julio de 2019).

El relato de G. en relación con sus responsabilidades maternas demuestra cómo la necesidad de hacerse de lo mínimo necesario para su alimentación y vestimenta, la ausencia de contribuciones por parte de la figura paterna en los gastos y la falta de una alternativa laboral que permita solucionar estas circunstancias, la empujaron al narcotráfico. Pero, una vez que participa de estas redes, salir de ellas no es exactamente una opción: G. estaba expuesta a la violencia y chantaje constante de los narcotraficantes que no dudaban en decirle que la única forma de dejar la actividad era la cárcel o la muerte. Desde esta perspectiva, la cárcel fue la única solución accesible para ella en aquel momento.

El ejemplo de G. constituye un caso extremo en el que la movilidad transfronteriza redunda en una cadena de violencias. Pero no todas las mujeres viven el desplazamiento así. Para las involucradas en el comercio de ropa, accesorios, comida o verduras, las actividades transfronterizas (su movilización cotidiana hacia Foz) constituyen una suerte de empoderamiento. Uno que, como veremos, también las introduce a nuevas precariedades; que las expone a nuevas violencias, como, por ejemplo, al trato xenofóbico de los(las) brasileños(as). 
Pese a estas experiencias, la mayoría valoraba positivamente su inserción en estas movilidades transfronterizas: sólo ocho evaluaban de mala manera el trabajo del lado brasileño. ${ }^{14}$ Para 22 mujeres, cruzar a Foz era no sólo una opción laboral importante, sino que les había permitido interrumpir ciclos de violencia. En el caso de Lirio Blanco, el comercio informal callejero en Foz, el poder vender sin tener que responder a un jefe, le permitió reunir recursos económicos y también una fortaleza moral para frenar un ciclo de violencia económica y verbal ejercida por su expareja y su exsuegra. Ella reconoce los tratos discriminatorios por parte de la población brasileña, pero considera que se trata de "un mal menor", frente a las posibilidades de empoderamiento que el cruce fronterizo le proporciona. Para Rosa 2, cruzar al lado brasileño es una estrategia para mantener las ventas cuando el comercio del lado paraguayo decae: "Tomé la decisión porque allá, en Ciudad del Este, no vendía mucho. Vendía poco ya. Más o menos. Cayó la venta, como se dice. Y ahí me dijo mi marido: 'vamos allá al Brasil'. Y yo le dije: 'vamos'. Yo me quedaba en Ciudad del Este hasta medio día y, ahí, venía para acá" (Entrevista a Rosa 2, 25 de julio de 2019).

Pero, más allá de las oportunidades económicas/laborales, las mujeres también expresaron otras razones por las cuales consideraban que trabajar en Foz era positivo. Shakira y Mía señalaron que cruzar la frontera permitía acceder al espacio público y no tener que permanecer la mayor parte de su tiempo dedicadas a las tareas del cuidado y domésticas. Ellas asociaban esta posibilidad a su felicidad, explicitando que se "acostumbraron" a esta libertad. No solamente "querían cruzar el puente", sino que necesitaban hacerlo para sentirse bien:

Si no vengo, extraño. Extraño no venir, extraño estar acá, ¿Viste? Que, si estoy en casa, me quedo: me levanto a las 9:00 de la mañana. Ya no es más normal. Estar acá, acá me siento bien feliz, acá: me siento tranquila ya me acostumbré, ya (Entrevista a Shakira, 25 de julio de 2019).

${ }^{14}$ Entre ellas, EA, comerciante de ropa que mantiene un puesto callejero en Ciudad del Este: "por ejemplo, la persona que se va a trabajar comenta que es un poco difícil. Porque no se le trata bien [a las paraguayas]. Allá en Brasil, dice que se les trata diferente. En Brasil tratan diferente, porque nos dicen que somos ignorantes. 'Paraguayas ignorantes', así nos llaman. Gracias a dios, no he trabajado allá" (Entrevista a EA, 29 de julio de 2019). 
A mí me gusta estar acá, me gusta. Cuando no vengo, no sé: me entristece. Pero quiero venir, quiero pasar el puente. Tengo que venir, tengo que atravesar: me acostumbré. [Cuando no viene] estoy en casa limpiando, cuido a mi bebé. Yo lo cuido. Cuando vengo, se queda con mi mamá. Me gusta cruzar el puente, me hace feliz. Extraño a mis clientes (Entrevista a Mía, 19 de julio de 2019).

Más allá de los beneficios económicos y de la libertad ganada, cruzar al lado brasileño implica la posibilidad de hacerse de nuevos conocimientos y de valorar y expandir sus habilidades. Por ejemplo, Mía relata haber expandido sus conocimientos idiomáticos. La mayoría es guaraní hablante y debió apropiarse más del castellano y aprender el portugués para trabajar del lado brasileño:

Yo, antes, casi no hablaba castellano y el portugués. Cuando vine acá, empecé a aprender, a practicar. Hasta yo me sorprendo: yo antes era tímida, no hablaba, yo. A mí no me gustaba vender, en la época en que vendíamos empanadas [ella, sus hermanas y su mamá]. No quería vender. Sólo llevaba, ni siquiera ofrecer, simplemente me iba con mis hermanas. Y, ahora, aprendí a vender y a ofrecer. Es bien diferente (Entrevista a Mía, 19 de julio de 2019).

Retomando lo que explicitábamos anteriormente, estas actividades comerciales del lado brasileño también exponen a las mujeres a formas heterogéneas de violencia. Tales vulneraciones se inician antes de llegar a Foz, en el paso cotidiano por el Puente de la Amistad, donde se enfrentan al trato discrecional de las autoridades fronterizas.

\section{EN EL CRUCE}

Las mujeres que se emplean en el comercio ambulante en Foz (que cruzan el puente diariamente desde Ciudad del Este) relatan constantes episodios de violencia protagonizados por la policía paraguaya en los operativos para decomisar la mercancía que trasladan entre uno y otro lado de la frontera. ${ }^{15}$ Generalmente, las autoridades de Brasil y Paraguay mantienen un bajo nivel

${ }^{15}$ Se establece que cada persona mayor de edad puede cruzar la frontera de Ciudad del Este al lado brasileño con el valor equivalente a hasta 300 dólares estadunidenses en mercade- 
de fiscalización: el tránsito humano y de mercancías entre estos dos países es considerablemente más laxo que entre ellos y Argentina. Pero las mujeres también indican que el gobierno de Paraguay suele cambiar los regímenes e intensidades de la fiscalización de acuerdo con intereses estratégicos. La señora Orquídea, que desde hace 23 años atraviesa mercaderías de Ciudad del Este a Foz, explica que estos cierres de la aduana paraguaya vienen aumentando desde noviembre de 2018:

$\mathrm{Y}$, ahora, el cambio es que no podemos pasar nada. Terminó el periodo anterior. Porque, ¿Viste que yo, en un furgón, casi llena me iba? Llevaba zapato, ropa. ¿Y ahora qué? No tengo nada, jmira! [muestra su bolso de mercancías]. Desde enero [de 2019], la pasada ya estaba así. No: desde noviembre, diciembre [de 2018] que no se puede pasar más. Ahora más; todavía peor. Porque zapato y ropa no se puede pasar [...]. No sé, es la cuestión del presidente [de Paraguay]. Son coimas [sobornos]. Si nosotros somos un poquito: muy poquito, ¿viste? No llevamos mucho. Casi nada. No sé qué les pasa a los aduaneros. Nos culpan de todo (Entrevista a Orquídea, 31 de julio de 2019).

En las últimas semanas de julio de 2019, cuando desarrollábamos nuestra etnografía, Brasil y Paraguay empezaban las negociaciones para definir los usos y acuerdos sobre la hidroeléctrica de Itaipú, de ambos países. Como mecanismo de presión hacia las autoridades brasileñas, el gobierno paraguayo intensificó las fiscalizaciones en el puente, con el despliegue de la violencia policial hacia los pequeños comerciantes (la mayoría mujeres paraguayas). Lirio Blanco, reflexionando sobre estas circunstancias, explicitó que ellas contribuyen a reproducir la vulneración de los(las) comerciantes de los sectores más pobres, que desarrollan el contrabando a pequeña escala para subsistir. Según ella, los grandes comerciantes pagan los sobornos a las autoridades y atraviesan las mercancías sin problemas. Relató, también, cómo los pequeños comerciantes habían cortado el puente para protestar en contra de la agresión policial:

En Paraguay, la aduana está atajando todo. Ahora, nomás. Porque ayer hubo un muchacho. Dicen que quería pasar mercadería y no quería entregar. Y le

rías (los menores de edad pueden llevar la mitad). Las personas que exceden este valor deben pagar el impuesto aduanero. 
baleó un policía. Por eso que están haciendo huelga, ahora [los(las) comerciantes]. Aquí la gente pasa mercadería y no él quería entregar su mercadería. Y la policía no tenía nada que ver, solamente. Tenía que ser aduanero lo que quitaba. Pero el marino, no tenía nada que ver, y le tiró, le cortó, le trozó toda su mano y también su cara, con balines de goma. Le quemó todo: por eso que está cerrando ahora. Paraguayo, un muchacho [...]. Hoy en día, los aduaneros no dejan más: los militares agarran todos y retiran [los productos] de cualquier persona. No tienen más compasión de la gente para tirar la balacera, de aquí para allá. Y había que protestar, la gente que pasa mercadería. Porque nosotros necesitamos unos de otros, necesitamos. Por ejemplo, yo trabajo acá y yo llevo otra vez mercadería. Yo compro, por ejemplo, una mercadería, una caja. Para donar de coima [soborno] 100000 guaranís, es mucho. Es difícil de trabajar. La gente pobre, si lleva mucha [mercadería] ya tienen problema. Porque paga para pasar. Por eso que la pobreza hay más, más y cada día más: porque la gente trabaja poco, no puede trabajar porque sacan todo lo que lleva. Y la gente que trabaja grande [comerciantes de gran escala], paga y pasa rápido, no tiene problema (Entrevista a Lirio Blanco, 23 de julio de 2019).

Como Lirio Blanco, diversas entrevistadas cuentan que las autoridades paraguayas usualmente piden sobornos para dejarlas pasar mercancías sin el pago de impuestos. Silvia complementa estas afirmaciones, explicitando que cuando se decomisan las mercaderías de los pequeños comerciantes, sus núcleos familiares quedan varios días sin recursos. Ella misma se considera con suerte porque sólo le decomisaron toda la mercadería una vez: "Solo una vez en aduana que me quitaron; una vez gracias a dios que me quitaron [...]. Fue tremendo, perdí mucho. Pero igracias a dios!, sigo aquí" (Entrevista a Silvia, 16 de julio de 2019).

El incremento de la fiscalización por parte de las autoridades paraguayas provoca desbarajustes vitales que no refieren solamente al comercio. Algunas de las comerciantes llevan consigo a sus hijos, pues no pueden tercerizar sus cuidados. En diversas ocasiones, el cierre del paso por la intensificación de la fiscalización afecta a sus dinámicas familiares y de cuidados, exponiéndolas a ellas y a sus hijos a vulneraciones variadas: "El cierre de la aduana es difícil. Eso, a veces, tienes que quedar en la fila mucho tiempo. Una vez quedamos con mi hijo en la fila: no teníamos agua, comida. Mi hijo enfermo, estaba agripado. No teníamos agua [...]. Quedamos entramos de las 9:30 h, 
supongamos, a las 4:00 h de la tarde, que pasamos a Paraguay. Eso es lo peor: y con mi hijo enfermo, agripado" (Entrevista a Shakira, 25 de julio de 2019).

Shakira explica, además, que el cierre de la frontera afecta al comercio de Foz: "No podemos trabajar. O venimos y no vendemos nada, porque no hay nadie: no hay plata. Cuando cierran el puente, no vienen paraguayas y paraguayos a comprar porque no pueden entrar" (Entrevista a Shakira, 25 de julio de 2019).

Pero no solamente las autoridades paraguayas protagonizan estas escenas de violencia en el control fronterizo. Talía describe cómo algunos militares brasileños perpetran violencia verbal y psicológica contra las paraguayas que cruzan la frontera. Hace hincapié en que esto se motiva doblemente por el machismo y por la xenofobia:

Es que los hombres son machistas. Mucho machismo y te maltratan. Acá mismo, en aduana en Foz, los militares que están ahí, que no quieren saber nada de las mujeres, igual te agarran te sacan todo [la mercadería]. Te dicen cosas y te maltratan. Tienen que decirte verbalmente, psicológicamente: te trabajan, te dicen cosas que no tienen sentido. Por ejemplo: "ustedes son paraguayas no tienen derecho a venir acá; no tienen derecho a trabajar, váyanse a la mierda en su país" [...]. Hay algunos que dejan mucho que desear como profesionales que son. Porque son profesionales los que están ahí, supongo. Supongo que estudiaron bastante, que saben de psicología. No sé, de algo. Pero, realmente, no saben realizar su trabajo (Entrevista a Talía, 17 de julio de 2019).

\section{DEL LADO BRASILEÑO}

\section{En el comercio ambulante}

Del lado brasileño de la frontera, las mujeres comerciantes callejeras y ambulantes fueron las que relataron experiencias de violencia en la vía pública. Según Shakira, que vende empanadas y tapioca en una mesita despegable en las calles de Foz, las actividades comerciales generan situaciones relacionales ambiguas. El buen funcionamiento del negocio, la posibilidad de acercarse a la competencia local depende, dice, de establecer un trato cordial y amable con los(las) compradores(as). Pero los clientes suelen interpretar esta cordialidad de forma liminal: la usan como un enganche para ofrecerles intercambios 
de otro orden, buscando establecer relaciones sexuales con ellas a cambio de remuneración. Las mujeres narran estas circunstancias a partir de dos registros que son contradictorios, pero simultáneos. Ellas relatan sentir estas interacciones como una vulneración y expresan tener miedo de algunos hombres dada la violencia de su abordaje (y porque, trabajando en la calle, están expuestas a que ellos las secuestren, las violen en los callejones o en las barrancas poco iluminadas del rio Paraná). Pero, al mismo tiempo, también relatan que se sienten obligadas a sobrellevar estas situaciones, pues enfrentarse con los hombres que actúan así provocaría problemas para la venta de sus productos:

Yo me siento bien trabajando, vendiendo. A lo primero era un poco difícil, porque todo mundo no me conocía porque acá los muchachos te molestan. Te hinchan: te quiere hacer de menos si vos trabajas en la calle. A veces te ofrecen plata, piensan que ganas menos y te quieren pagar para salir con ellos. Algunos te ofenden acá. Eso es lo que pasa. Acá la mayoría de los hombres son así. Te dicen ellos: “¿Quieres salir conmigo? Te puedo ayudar”. Así ya vinieron muchos. Ahora ya no, porque ya me conocen. Les decía que "no", que no era así. Pero no les quería hacer enojar. Y les dije: "yo vine a trabajar". No quería retar, porque no me iban a comprar más chipas [pan de yuca]. Les decía "yo tengo marido" y cosas así. Así les decía. Y ahora ya me conocen. Si no vengo acá a trabajar ya extraño. Porque me acostumbré: yo llego en la mañana, me tomo un mate. Ellos vienen, toman mate conmigo, me hablan. Me conocen: son como parte de la familia. Me conocen ya. Parte de la familia son (Entrevista a Shakira, 25 de julio de 2019).

El testimonio de Shakira permite establecer que la liminalidad que caracteriza las relaciones sociales y económicas en esta frontera repercute en la exposición de las mujeres a formas violentas de abordaje; pero que la salida a esta situación no se plantea a través de estrategias de oposición drástica a estos diálogos y/o el desarrollo de conflictos con los interlocutores, sino que estableciéndose un particular sistema de alianzas. Las relaciones comerciales son entendidas como ambiguas por unas y otros: como pasibles de ser convertidas en intercambios sexuales. Pero Shakira también explicita que los hombres testean a las mujeres para saber qué tan lejos pueden ir, antes de cruzar la frontera entre intercambio comercial e intercambio sexual remunerado. Ellos ofrecen estos últimos explicitándolos en términos de un paternalismo protector: "te puedo ayudar". Si la mujer se resiste, invocando a los mandatos 
"de buena mujer" ("vengo a trabajar", "tengo marido"), las invitaciones cesan. $\mathrm{Y}$ estos mismos hombres que las invitaban a la prostitución, terminan por aceptar el límite negociado y devienen sus clientes. Les compran sus productos, comparten mate y conversan tranquilamente día con día.

Se establece, así, un lazo de otro orden: el intercambio entre unas y otros está clarificado y permite el establecimiento de una convivencia cotidiana. Los hombres ya no ofrecen plata por sexo, porque, según Shakira, "la conocen". Cuando ella habla de ellos como "su familia", nos da indicaciones centrales en términos simbólicos. Entre ella y ellos rige una alianza de intercambios con sentidos establecidos a partir de su definición dialógica con ellos de que no cruzaría el límite hacia el sexo remunerado. La definición de este posicionamiento, su situacionalidad en relación con el límite que los hombres buscaron testear, permite que la vinculación avance hacia un régimen alianza, un sistema de prestaciones totales, para aludir a la categoría antropológica clásica. En otras palabras, este sistema de prestaciones y cordialidad mutua se establece a partir de la negociación de los límites de Shakira y de la explicitación del tipo de mandato de género a que está adscripta. Y los hombres "son familia", porque con ellos hay un vínculo permanente, de intercambio controlado, que establece una forma específica (una frontera interaccional, diríamos) para un interdicto sexual.

Pero aun del lado brasileño, en Foz, las mujeres paraguayas mencionan otras formas de peligro callejero, vinculadas a la presencia de consumidores de "crack" $"$ que amenazan constantemente con asaltos y robos. Lirio Blanco menciona que la respuesta de las vendedoras callejeras a estos problemas pasa por dos medidas. Por un lado, no involucrarse con dichos consumidores (en la frontera todos(as) están llamados a adaptarse a la pluralidad de movimientos, personas y usos legales/ilegales del espacio público). Por otro, establecer sistemas de cuidados entre las propias mujeres que venden para protegerse mutuamente: "Acá, todo el día, la gente libremente fuma acá. Pasando, fumando [crack]. Eso hay: hay muy, mucha gente que son muy peligrosos. Pero si vos no haces caso de ellos, también ellos no te hacen caso. Estamos

${ }^{16}$ Droga derivada de la cocaína que se vende en piedras para ser fumadas. Provoca niveles elevados de dependencia química, una acelerada destrucción física y la rápida ruptura de vínculos sociales. Es muy popular en Brasil, estando asociada a los delitos callejeros perpetrados por sus consumidores para sostener el uso. 
bien, no hay peligro. Porque estamos mucha gente, y todos cuidan uno de otro" (Entrevista a Lirio Blanco, 23 de julio de 2019).

Finalmente, habría que considerar que, para muchas mujeres, la opción de trabajar como comerciante ambulante constituye una estrategia de resistencia a las discriminaciones y explotaciones laborales. De acuerdo con EPM, el autoempleo como comerciante callejera en Foz constituye una alternativa para eludir a la violencia laboral que las paraguayas se enfrentan por parte de patrones brasileños. Menciona, además, que dicha violencia se gesta por un sentimiento de superioridad de los(las) brasileños(as) hacia la población paraguaya. Así, pese a la precariedad que implica el autoempleo ambulante -por la ausencia de un contrato que asegure las prestaciones sociales y un sueldo fijo; o por la falta de un cobijo para protegerse de las intemperies climáticas- nuestras entrevistadas lo consideran una mejor opción que trabajar para un(a) patrón brasileño(a):

Los patrones que quieren maltratar al funcionario. Digo yo. Porque se sienten muy encima: quieren maltratar. Yo, por eso, ya no trabajo para los otros. Cuando aparece algo para hacer, yo me voy: trabajo uno o dos días. Si es por una semana trabajar, yo trabajo. Pero fijo, trabajar solo en un lugar, yo no trabajo, por eso: porque quieren maltratar, se sienten muy encima de uno. Y, entonces, eso no está bien [...]. A veces nos quieren tratar como perros, a uno. Pero, así, en la calle, nadie hace caso. O sea; nadie te discrimina, nadie nada. Porque estás trabajando propio: nadie te puede decir nada. Pero, ahora, si trabaja para los otros, ya te tratan mal (Entrevista a EPM, 11 de octubre de 2018).

\section{En el comercio establecido}

Pero las interacciones humillantes, vulneradoras, discriminadoras de parte de los(las) compradores(as) no ocurren solamente para las mujeres que venden en las calles del lado brasileño: también constituyen una situación cotidiana para las que trabajan en las tiendas más establecidas. Sonia, que llevaba tres años trabajando en una tienda de ropa y calzado del barrio de Vila Portes (aledaño al puente), relató que: "No es fácil ser vendedora en Foz: es muy complicado. Vos, siendo vendedora, tenés que aguantar muchas cosas. Hay unos que vienen, te insultan, te hablan. Hay muchas cosas. Entonces tenés que tener una gran paciencia para ser vendedora" (Entrevista a Sonia, 16 de julio de 2019). 
Según explicó, las violencias sufridas por las vendedoras paraguayas son particularmente intensas de parte de las mujeres brasileñas que, desde su perspectiva, se sienten "amenazadas" con su presencia (las paraguayas tienen fama de ser cordiales, bonitas, buenas trabajadoras y dóciles; atributos que, supuestamente, las convierte en una preferencia masculina). Para resistir a esta conflictividad competitiva entre mujeres de las dos nacionalidades, las trabajadoras paraguayas que se insertan en el comercio de Foz establecen redes de solidaridad mutua, usando el idioma guaraní (no dominado por los[las] brasileños [as]) como un código comunicacional protector:

Ellas [las brasileñas] llegan, no te hablan ni te saludan. Y cuando están celosas, ni te hablan; ni te miran. Porque nosotras somos vendedoras: nosotras tenemos la obligación de llegar al cliente y sonreír, saludar, preguntar qué necesitan. Preguntar si necesitan ayuda. Y, bueno, hay algunas brasileras a las que no les gusta eso. Cuando está con su pareja, se siente tipo amenazada por la vendedora [paraguaya]. Cuando llega alguna paraguaya, y encuentra que, por ejemplo, yo soy paraguaya... Y ahí ya nos llevamos bien: sonreímos y comenzamos a hablar en nuestro idioma. Entonces, con una brasileña es diferente (Entrevista a Sonia, 16 de julio de 2019).

Aquí, vemos cómo la solidaridad establecida entre las mujeres paraguayas del lado brasileño va ganando tintes étnicos. Esto porque la diferencia de idiomas (el uso particular del guaraní por parte de las paraguayas) establece al mismo tiempo un límite diferenciador entre ellas y las brasileñas, y un elemento de protección que las resguarda de la animosidad del entorno.

Clara evidencia de otro tipo de violencias en el espacio laboral, pero esta vez perpetrado por las compañeras de trabajo brasileñas. Estas establecen límites xenofóbicos hacia las paraguayas, asumiendo que el hecho de trabajar en su propio territorio nacional debiera asegurarles más derechos $y$, además, la potestad de maltratar a las extranjeras:

Mucha gente sufre discriminación. Hay mucha gente que... No es la patrona la que te maltrata: son las compañeras. Son las compañeras brasileñas, las que maltratan a las colegas. Son las colegas las que más escucho, así, que les tratan mal a las paraguayas. Porque ellos se creen porque están en su país. Como que tienen más derechos porque nosotros estamos en su país [...]. He escuchado 
tanta gente contándome cosas así ¿No? Me da la impresión de que, aquí, los brasileros se creen mejores (Entrevista a Clara, 11 de octubre de 2018).

Es precisamente Clara quien explicita que las experiencias de abuso por parte de los(las) brasileños(as) en Foz son comunes y caracterizan la cotidianidad laboral de las mujeres paraguayas en esta ciudad: "ya conocí a mucha gente que ha sufrido" (Entrevista a Clara, 11 de octubre de 2018).

\section{Trabajadoras domésticas}

Mía, que se empleó como asesora doméstica en Ciudad del Este desde los 15 años hasta los 21, describe cómo las relaciones de confianza y afecto que cultivó con sus empleadores habilitaron que estos vulneraran sus derechos laborales. Por ejemplo, la presionaban para suspender su tiempo de descanso cuando les convenía y evitaban pagarle las horas extra:

[La empleadora] era muy buena, buenísima. Sí, pero después fue acostumbrándose. Porque yo le daba su gusto también: me quería demasiado después. Tres años duré. Es que a mí no me gusta trabajar tanto tiempo. Cuando ya se acostumbran a ti es que ya, después, te hacen trabajar en cosas que no corresponden a tu trabajo. Y, entonces, salí de ahí. Como yo dormía ahí, ellos me despertaban para que cuidara a la nena. Y ellos se iban a bailar, a tomar en la noche. Y eso a mí no me gustaba. Me pagaban, pero no me pagaban por cuidar a la nena de noche. Y, ahí, salí de ellos. Sí, porque ya no me gustaba más (Entrevista a Mía, 19 de julio de 2019).

Relató, además, que enfrentó circunstancias parecidas en otro trabajo como empleada doméstica que tuvo posterior a este, entre los 21 y 24 años, pero en Foz. Tras casi nueve años de experiencias de abuso en este rubro, Mía decide autoemplearse en el comercio fronterizo, comprando y vendiendo ropa usada del lado brasileño de la frontera. María 1, de origen rural, describe las violencias verbales sufridas por parte de sus empleadores cuando, recién llegada del campo en Paraguay, fue a trabajar a una casa particular de Foz:

Cuando llegué a Foz, yo trabajaba como criadita. Al llegar ya trabajaba como criadita. Eso es, que te vas con una señora a trabajar, que te manda a hacer 
toditas las cosas, todos los días [...]. Sí, 4 años trabajé así [...]. Cuando eres chiquitita no piensas nada. A veces te retan porque haces las cosas mal, la verdad. Porque venir del campo a la ciudad es diferente. No saber qué es electricidad, por ejemplo. Yo no sabía qué era electricidad. Allá nosotros no teníamos. A veces te retaban y otras todo bien. No me pagaban; era más por la comida y el hospedaje (Entrevista a María 1, 25 de julio de 2019).

Cuando les preguntamos a las mujeres por qué se subordinaban a estas formas de maltrato laboral por parte de los(las) empleadores(as) brasileños(as), muchas explicaron que aguantaban por necesidad. Explicitaron que los(las) empleadores(as) saben de las dificultades que atraviesan las mujeres paraguayas a la hora de conseguir un trabajo fijo que permita solventar la manutención de su hogar. Los(as) empleadores(as) juegan con esta necesidad, estableciendo con ellas una relación perversa:

Ella [su empleadora brasileña] es así: te mira, así, debajo de la lente; encima de la lente. Te mira así. Ella es un poco complicada para entenderse bien con ella. Pero ahí estoy aguantando; son dos años ya. Por falta de... Es que, como yo no conozco muy bien, para trabajar en otro lado y tengo que tener un trabajo fijo. Porque, por ejemplo, yo pago 350 [reis] en mí alquiler. Tengo que pagar la luz, tengo que pagar el agua, tengo que comprar para mi comida. Esas cosas. Entonces, tengo que aguantar las cosas. Algunos empleadores buscan de la persona por causa que saben que no va a salir, porque necesita. Y, por eso, ella abusa así (Entrevista a RBA, 11 de octubre de 2018).

\section{CONSIDERACIONES FINALES}

En este artículo, identificamos que las mujeres paraguayas enfrentan experiencias multidimensionales y polifacéticas de violencia que están vinculadas a marcos simbólicos sexistas. Estas violencias se configuran de formas particulares en el espacio público de Ciudad del Este, en el cruce fronterizo y en Foz de Iguazú. Identificamos que las movilidades femeninas -tanto desde sus localidades rurales de origen a Ciudad del Este, como hacia Foz de Iguazú- constituyen una búsqueda por esquivar y sortear dichas experiencias. Nuestro estudio permite afirmar que, en esta movilidad transfronteriza, 
las mujeres experimentan una dialéctica entre la reproducción y la interrupción de la violencia. Cuatro ejemplos nos ayudarán a graficar esta afirmación.

Primero, si bien los desplazamientos hacia el lado brasileño les permiten superar la dependencia económica y la violencia física de sus parejas en el espacio doméstico en Paraguay, las expone a la violencia de las redes del narcotráfico, o a la discriminación xenófoba y racial por parte de la población brasileña en el espacio público. En el caso de las comerciantes que trabajan en las calles brasileñas, las expone a la violencia sexual (ante ofrecimientos de relaciones sexuales remuneradas, de parte de sus clientes y la probabilidad de que sean asaltadas por los consumidores de drogas, o de que sean violadas en los callejones de Foz).

Segundo, vimos que el cruce fronterizo posibilita a las mujeres esquivar su sobrecarga de labores de cuidado y domésticas, traspasándolas a madres y hermanas. Esta posibilidad es tan relevante para ellas, que varias de nuestras entrevistadas asociaban el cruce del puente, el poder trabajar en las calles en vez de cuidar todo el día, como sinónimo de felicidad (algunas lo asociaron a la salud mental, incluso). Así, el que puedan salir a vender en las calles y a cruzar la frontera les reduce sobrecargas del trabajo de reproducción sexual que los mandatos patriarcales definen como "tareas femeninas". Pero esto deviene en la sobrecarga de otras mujeres de sus familias, quienes se quedarán a cargo de estos cuidados. Así, el cruce fronterizo, facilita experiencias femeninas de "felicidad" y "libertad", pero reproduciendo la sobrecarga femenina y subrogándola a otras mujeres, sin un redimensionamiento de la división sexual del trabajo de cuidados.

Tercero, pese a las violencias vividas de parte de las autoridades en los cruces fronterizos, y a las discriminaciones y peligros en el lado brasileño, los movimientos transfronterizos también permiten que las mujeres accedan a conocimientos que no están disponibles para ellas en Paraguay. Ejemplo de ello es el dominio de nuevos idiomas y los conocimientos sobre cómo sostener las actividades comerciales (desde la compra de mercancías, hasta el trato con clientes). Estos nuevos conocimientos les abren más oportunidades de inserción laboral (en el comercio establecido formal, o en el callejero y ambulante) que les permiten establecer nuevos horizontes de futuro para ellas y sus hijos(as).

Cuarto, en el espacio privado de casas de Foz donde las paraguayas trabajan como empleadas domésticas, los vínculos establecidos con los empleadores son caracterizados, simultáneamente, por una afectividad mutua y por 
la reincidencia de una explotación de sus labores. Así, el cariño de los "patrones" aparece como un mecanismo integrador para estas mujeres $y$, al mismo tiempo, como un reproductor de mandatos de género que refieren a su sobrecarga laboral como cuidadoras en el trabajo doméstico.

En síntesis, el espacio transfronterizo constituye una articulación de diferentes configuraciones de la violencia de género. Si bien la movilidad femenina profundiza esta violencia en sus manifestaciones estructurales y relacionales, también permite, dialécticamente, que las mujeres construyan mecanismos de resistencia y se empoderen con la negociación de sus roles y de los significados de su presencia en el ámbito privado y público.

\section{LISTA DE REFERENCIAS}

Agulló, J. (2017). Una revisión geopolítica de la Triple Frontera del Paraná. En W. Soto (ed.), Repensar las fronteras. La integración regional y el territorio (pp. 59-69). Heredia: Consejo Latinoamericano de Ciencias Sociales.

Alberti, V. (2005). Manual de história oral. Rio de Janeiro: FGV Editora.

Albuquerque, J. (2012). Limites e paradoxos da cidadania no território fronteiriço: $O$ atendimento dos brasiguaios no sistema público de saúde em Foz do Iguaçu (Brasil). Geopolitica(s), 3(2), 185-205. DoI: http://dx.doi.org/10.5209/rev_GEOP.2012. v3.n2.40040

Arriola, E. (2007). Accountability for murder in the maquiladoras: linking corporate indifference to gender violence at the US-Mexico border. Seattle J. Soc. Just, 5(2), 603-629. Recuperado de https://digitalcommons.law.seattleu.edu/sjsj/vol5/ iss $2 / 29$

Báez, M. (2017). Trabajo doméstico precarizado en la triple frontera. (Tesis de licenciatura). Facultad de Ciencias Sociales-Universidade Federal de Integração Latino-Americana, Brasil.

Barrero-Valinotti, A. (2011). Mujeres que hicieron historia en el Paraguay. Asunción: Servilibro-Ateneo Cultural.

Barrero-Valinotti, A. (2013). Las mujeres. Asunción: El Lector.

Barvinsk, G. (2014). La trata de mujeres con fines de explotación sexual en la región de la triple frontera. Revista Latinoamericana de Estudios de Seguridad, 14, 68-78. DoI: https://doi.org/10.17141/urvio.14.2014.1344

Bethell, L. (1996). The Paraguayan war (1864-1870). Londres: University of London. Bourdieu, P. (1998). La dominación masculina. Barcelona: Anagrama. 
Butler, J. (2011). Replantear el universal: la hegemonía y los límites del formalismo. En J. Butler, E. Laclau y S. Zizek (eds.), Contingencia, hegemonía, universalidad: diálogos contemporáneos de la izquierda (pp. 19-50). Buenos Aires: Fondo de Cultura Económica.

Costa, T. y Schulmeister, G. (2007). The puzzle of the Iguazu tri-border area: Many questions and few answers regarding organised crime and terrorism links. Global Crime, 8(1), 26-39. DoI: https://doi.org/10.1080/17440570601121845

Cury, M, J. F. y Fraga, N. C. (2013). Conurbação Transfronteiriça e o Turismo na Tríplice Fronteira: Foz Do Iguaçu (Br), Ciudad del Este (Py) e Puerto Iguazú (Ar). Rosa dos Ventos, 5(3), 460-475. Recuperado de http://www.ucs.br/etc/revistas/ index.php/rosadosventos/article/view/2253

Expósito, F., Moya, M. y Glick, P. (1998). Sexismo ambivalente: medición y correlatos. Revista de Psicología Social, 13(2), 159-169.

Garriga, J. y Noel, G. (2010). Notas para una definición antropológica de la violencia: un debate en curso. Publicar, 8(9), 97-121.

Guber, R. (2001). La etnografía: método, campo y reflexividad. Buenos Aires: Editorial Norma.

Guizardi, M. L., López, E., Nazal, E., Valdebenito, F. (2017). Fronteras, género y patriarcado. Discusiones teóricas para replantear el transnacionalismo migrante. LÍMITE Revista Interdisciplinaria de Filosofía y Psicología, 12(38), 22-38. Recuperado de https://www.revistalimite.cl/index.php/limite/article/view/69

Hernández, A. y Rodríguez, A. (2015). El sexismo como una práctica de violencia en la universidad. Revista de Educación Social, 21. Recuperado de https://eduso.net/ res/revista/21/el-tema-experiencias-investigaciones/el-sexismo-como-una-practi ca-de-violencia-en-la-universidad

Kleinschmitt, S. (2016). As mortes violentas e as políticas de controle na Tríplice Fronteira. Tempo da Ciência, 23(46), 40-59. DoI: https://doi.org/10.48075/rtc. v23i46.16128

Lamas, M. (1986). La antropología feminista y la categoría "género". Nueva Antropología, 8(30), 173-198. Recuperado de https://www.redalyc.org/articulo. oa?id=15903009

Lamas, M. (1998). La violencia del sexismo. En A. Sánchez Vázquez (ed.), El mundo de la violencia (pp. 191-198). México: Fondo de Cultura Económica.

Lamas, M. (1999). Usos, dificultades y posibilidades de la categoría género. Papeles de Población, 5(21), 147-178. Recuperado de https://www.redalyc.org/articulo. oa?id=11202105

Lévi-Strauss, C. (1969). Estructuras elementales del parentesco. Barcelona: Paidós. 
Lugo, A. (1990). Cultural production and reproduction in Ciudad Juárez, México: Tropes at play among maquiladora workers. Cultural Anthropology, 5(2), 173-196. Recuperado de http://www.jstor.org/stable/656455

Mills, M. (2003). Gender and inequality in the global labor force. Annual Review of Anthropology, 32, 41-62. DoI: https://doi.org/10.1146/annurev.anthro.32.061002.093107

Molina, F. (1985). The social impacts of the maquiladora industry on mexican border towns. Berkeley Planning Journal, 2(1), 30-40. DoI: https://doi.org/10.5070/ BP32113197

Monárrez, J. (2013). Trama de una injusticia; feminicidio sexual sistémico en Ciudad Juárez. Ciudad Juárez: El Colegio de la Frontera Norte.

Morales, M. y Bejarano, C. (2009). Transnational sexual and gendered violence an application of border sexual conquest at a México-US border. Global Networks, 9(3), 420-439. Dor: https://doi.org/10.1111/j.1471-0374.2009.00261.x

OIT [Organización Internacional del Trabajo] (2002). Políticas sociales y oferta institucional para la confrontación de la explotación sexual comercial de niñas, niños y adolescentes en la frontera Paraguay-Brasil. Ciudad del Este: Autor.

Potthast, B. (2001). Residentas, destinadas y otras heroínas: El nacionalismo paraguayo y el rol de las mujeres en la guerra de la Triple Alianza. En B. Potthast y E. Scarzanella (eds.), Mujeres y naciones en América Latina, problemas de inclusión y exclusión (pp. 77-91). Madrid: Vervuert Iberoamericana.

Potthast, B. (2006). Algo más que heroínas. Varios roles y memorias femeninas de la guerra de la triple alianza. Diálogos, 10(1), 89-104. Recuperado de https://periodicos.uem.br/ojs/index.php/Dialogos/article/view/41381

Profit, A. (2015). El hombre soy yo. Dinâmicas familiares no contexto da imigração paraguaia no Brasil. (Tesis de maestría). Centro de Pesquisa e Pós-graduacao sobre as América, Universidad de Brasilia, Brasil.

Renoldi, B. (2013). Fronteras que caminan: relaciones de movilidad en un límite trinacional. Revista Transporte y Territorio, 9, 123-140. Dor: https://doi.org/10.34096/ rtt.i9.307

Sausi, R. y Oddone, N. (2010). Cooperación e integración transfronteriza en el Mercosur: el caso de la Triple Frontera Argentina-Brasil-Paraguay. En L. Maira (ed.), La política internacional subnacional en América Latina (pp. 209-258). Buenos Aires: Del Zorzal.

Seaman, B. (2012). Cry for me Argentina. The commercial sexual explotation of children in south América. Law now. Recuperado de https://www.lawnow.org/com mercial-sexual-exploitation-of-children-in-south-america/ 
Segato, R. (2010). Las estructuras elementales de la violencia. Ensayos sobre género entre la antropología, psicoanálisis y los derechos humanos. Buenos Aires: Prometeo.

Segato, R. (2013). La escritura en el cuerpo de las mujeres asesinadas en Ciudad Juárez. Territorio, soberanía y crímenes de segundo estado. Buenos Aires: Editorial Tinta Limón.

Segato, R. (2016). La guerra contra las mujeres. Madrid: Traficante de Sueños.

Soto, C. (2009). Marcas culturales para las mujeres en la sociedad paraguaya. Ponencia presentada en el Primer Foro Internacional del Bicentenario, Asunción, Paraguay.

Souchaud, S. (2011). A visão do Paraguai no Brasil. Contexto Internacional, 33(1), 131153. DoI: https://doi.org/10.1590/S0102-85292011000100006

Tarducci, M. (2006). "Tráficos fronterizos": introducción a la problemática de la adopción de niños en Misiones, Argentina. Cadernos Pagu, 26, 45-47. Dor: https:// doi.org/10.1590/S0104-83332006000100003

Téllez, M. (2008). Community of struggle: Gender, violence, and resistance on the US/Mexico border. Gender \& Society, 22(5), 545-567. DoI: https://doi. org/10.1177/0891243208321020

Woo, O. (2004). Abuso y violencia a las mujeres migrantes. En T. Fernández (coord.), Violencia contra la mujer en México (pp. 71-83). Ciudad de México: Universidad Nacional Autónoma de México.

Yuval, N. (1993). Gender and nation. Ethnic and Racial Studies, 16(4), 621-632.

Zsögön, M. (2013). Explotación sexual comercial infantil en la Triple Frontera entre Argentina, Brasil y Paraguay. Ideação, 15(2), 110-128. DoI: https://doi.org/10.48075/ ri.v15i2.8777 